\title{
A Research on the Performance Communication Questions in Enterprise Performance Management
}

\author{
Zhiwei Li \\ Business Departments \\ Henan University of Animal Husbandry and Economy \\ Zhengzhou, China \\ Lzwred@163.com
}

\begin{abstract}
The effective performance management is an important part to promote the personnel quality and realize the organization goal. Moreover, the performance communication is the key of performance management, playing a vital role in every link in performance management. But due to the problems such as "the managers conception", "result overweighing process", the current performance communication way is not good for improving staff quality and performance continuously. Therefore, from the following four aspects: ideological recognition, information collection, communication skills, and performance management, grasping the key point of performance communication, and taking measurements which can maintain continuous and effective communication, is very important to solve the performance communication problem, and enhance the enterprise performance.
\end{abstract}

Keywords- Performance management; Performance communication; Skills of communication

\section{INTRODUCTION}

With the coming of knowledge economy and fierce market competition, the core competitiveness of enterprises tend to transfer from capital and technology to the human resources. It is also said that the decisive factor of each organization in the competitive market position is "human". Organizations in China pay more attention to human resource management. Owing to the importance degree of performance management in human resource management, effective performance management is the key link to improve the staff quality and realize the target of organization. The significant reason why performance management has been applied in every organization but little progress achieved lies in the lack of communication. For instance, if managers do not keep continual and effective communication with the staff, it would be difficult to get employees' feedback information of their performance and be timely support to solve their difficulties and problems. In the other hand, as the manager, it is also difficult in helping employees constantly improving and enhancing staff performance, and grasping the behavior of employees and staff performance orientation. In words, as long as the effective communication carries on the whole process of the performance management, the performance management can be promoted effectively.

\section{THE RELATIONSHIP BETWEEN PERFORMANCE COMMUNICATION AND PERFORMANCE MANAGEMENT}

Performance management is to develop employee performance targets and collect the information related to the performance, for the completion of the performance goals for employees on a regular basis to make evaluation and feedback, to improve the employee's work performance and eventually improve the overall performance of institutionalized process. We think that performance management is based on continuous performance communication, through the performance plan (P), (D) implementation performance, performance appraisal, (C) (A) and performance feedback four stages of loop operation, to achieve organizational goals and employee development the dynamic management process. Meaning, performance management itself represents an idea and thoughts, representing the system for enterprise performance issues related to thinking. Figure 1 as a result, we can use to represent the relationship between performance management and performance in different stages of the communication, put forward suitable for China's enterprises to implement the performance management mode. Figure 1, the performance of communication is the soul of the whole performance management activities, throughout the whole process of performance management. The performance management mode emphasizes the core status of performance communication; points out that the performance in any stage of the performance management communication is the core of the must do work. The model managers will be at the center of the whole management process, adjust the masterslave status of managers and by managers, which ensures the attention it deserves to be managers

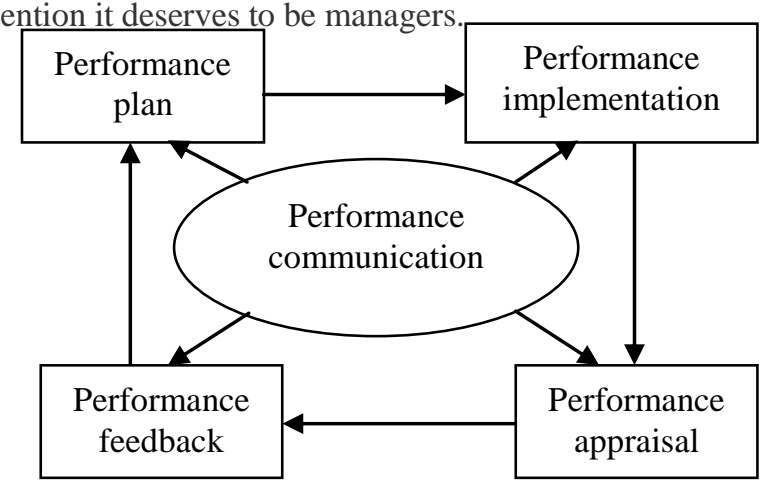

Figure 1 flow chart of performance management system 
At present, the performance of communication as a concept, and applied to the whole process of performance management related research has just started. Performance management method is introduced from the west to reflect the existence of the communication in the performance feedback, in fact, in the process of implementation of communication throughout the course of the performance management of the foreign capital enterprise management practice in our country can be clearly seen. Because our country socialist market economy to establish relatively late, the introduction of western management methods of the time is shorter, the professional quality of the employees at all levels is generally low, so you have to introduce suitable for developed countries to adjust the state of the human resource management method. To some extent, the communication is the essence and core of performance management, it runs through the performance management cycle, always want to communicate with the target, performance planning, help employees to achieve goals to communication, year-end assessment to communicate, analyze reasons for progress to communication. In short, performance management is the process of constant communication, employees and their managers to enhance the performance of the process. Out of the communication, the enterprise performance management will become a mere formality. Once the work is based on rational, based on the principle of the criterion, communication become a habit, so will no longer need to communicate in a work as a link to emphasize. Based on such consideration, performance communication can be defined as managers and managers in the process of performance management of the two sides will work on the issue of performance communication.

\section{THE MAIN PROBLEMS EXISTING IN THE ENTERPRISE PERFORMANCE COMMUNICATION IN CHINA}

\section{A. Manager's less attention to performance communica- tion}

Many managers are not very attaches great importance to the performance of communication, especially the employee's direct supervisor. They do not conduct performance communication for three reasons: first, don't have the time. They often work in no time, too busy for reason and ignore the work, not the performance communication this link as their duty to work. Second, think that there is no need. Some managers think that scores for the employee's performance, fill in a form to complete the performance appraisal work. Even to give employees feedback will give a written the results of the line you don't talk about won't have any change for the results. Third, the managers lack of necessary communication skills. Some managers because there are no appropriate skills or whether harmonious communication with employees is a lack of confidence and therefore not willing to communicate performance.

\section{B. Talking more in vague generalities}

Generalizations are the common fault of the performance communication in common performance communication is also a no-no. Fuzzy information are often unable to play the role of performance communication should be, employees still do not know this how to improve, or improve head of content is not expected.

\section{The lack of upward communication on the lower level communication}

Performance communication should be common on the performance of managers and employees two-way communication process. But some managers because of the influence of the ranking of the thought, two-way communication, they don't value or like to play the role of judges, tend to criticize the shortcomings of subordinate. Either makes them, just the role of the audience. So managers haven't chance to subordinate ideas in the process of the work and the progress of the work and thus cannot be effectively understand problems and expectations, to make the right decisions, is not conducive to help employees to solve difficulties and problems, is not conducive to both sides come to an agreement and cooperation.

\section{Caring more about the result of communication than about the process}

In the process of performance management, managers only pay attention to the assessment on the final result of the employee, the results are, and then use this as the basis for rewards and punishments. The managers didn't pay attention to communicate with employees and coach the employees about performance on this basis. So many problems existing in the work in the process of performance management failed to solve, or to reach consensus. Usually in performance appraisal, the manager cannot resist some score-settling through saving all problems together with the staff by $t$ performance feedback. So it is likely to form a confrontational situation, and is unfavorable to continuous improvement and improves staff quality and performance.

\section{THE KEY POINT TO GRASP PERFORMANCE} COMMUNICATION, BY KEEPING EFFECTIVE COMMUNICATION

\section{A. Changing managers' mindsets to improve their know- ledge}

Thought is the forerunner of action, must carry on the effective performance of communication, enterprise managers should set up the correct understanding of the performance communication, employees on the correct guidance, make them set up the right attitude. First of all, enterprise managers give up some ideas seriously enough. From the point of view of the performance management process, performance communication throughout the whole process of performance management, every link in the process play an important role, and left the performance communication, any unilateral decision managers will affect employees work enthusiasm, influence the process of performance management. Can say, the whole process of performance management is in the communication and dialogue between managers and employees, therefore, no performance management of communication and dialogue, can't call it the performance management, also can't achieve 
the result of its supposed to achieve, will become a "chicken soup". In order to make the performance management in the normal orbit, really play its role, enterprise must take the performance of the communication between managers and employees as the pinnacle of performance management, research and development, make performance communication habit of management personnel, with employees in the work performance dialogue and communication to solve the problem, to implement performance management.

\section{B. Before communication, preparations must be made in earnest}

Forewarned is forearmed. Performance communication, only really reflected the results of the information, and communication objects to communicate the basis of "common language", or communication will be exist different degrees of diaphragm. Interpretation of the performance management results should complete four problems: first, the communication object should do; Second, the communications object what has been done; Third, why communication objects for the assessment results; Fourth, the communication object in which direction should be improved. In order to improve the performance of communication effect, before the performance communication should be prepared for the corresponding work. Specifically, the preparation of information and communication performance communication content includes the following aspects:

1) Accomplishments of periodical work objectives, task

This aspect should be progress review, job description and work plan, and communicate every job completion, managers can post responsibility, to discuss item by item, the completion of the indicators, sure. This is mainly for employees a stage performance evaluation result exchange views in the past, to find a consensus.

2) Excellent performance in the process of work completed

Subordinate shines in the work, mainly mining list specific examples to prove the best. This communication requires managers to observe and discover in daily work of the outstanding staff, timely praise and a reward, to expand the positive effects of positive behavior. To do this, managers must first find the selling point of employee, like something not employee responsibilities within the scope of the active (even the smallest things) employee to complete, treat work results beyond standard or expected a lot. But be careful not to praise some commendable behavior, such as the employees should do. Secondly must be specific attention should be paid to praise; praise the content must be based on facts, attitudes to clear.

3) Clearly telling them where they can be better

Should be aimed at specific problems, made clear that employees work in the process of which places do not get a, what still can be improved. Please describe in staff I analysis the cause of the problem, the next step how to overcome and improve, at the same time put forward my own advice.
4) Assisting subordinates to establish improvement plan

To help subordinates to improve improvement measures and action plan, to the problems in the implementation process or need support to provide guidance and help.

5) The next phase of work objectives, performance planning and confirmation

Point is and staff to discuss and determine the work target, to complete the schedule and check the inspection plan, let employees to accomplish objectives, milestones, when feedback has a clear understanding.

\section{Mastering two skills performance communication and feedback skills -- listening skills}

Perfect appraisal system can make up for managers and staff lack of communication. Communication is the process of "say" and "hear", different communication ability, the effect of different. Language expression ability is very good, and also knows how to listen to others, can bring many positive effects to the performance of communication. At the time of communication, managers should pay attention to cultivating their own communication skills:

1) Listening skills

During the performance of communication, as a manager, first of all should cultivate their listening, listening is a kind of two-way communication, the purpose of listening is to make the most appropriate response, by listening to understand other people's opinions and feelings. The course needs a fitting to render and certain facial expression. As an effective listener, managers should be through their body language shows interest in subordinate conversation. Affirmative nod, appropriate expressions and supplemented by appropriate eye contact, no doubt shows: are you listen with your heart. Second, we must avoid the implied negative emotions. The actions, such as watching, reading newspaper, playing with a pen, show that you are very tired, is not interested in talking, no attention. Third, we need to present a natural open posture. Can through facial expressions and body posture show open communication, should not be crossed arms and legs, reach forward on when necessary, in the face of the other side, remove the obstacles between both sides, such as tables, books, etc.

2) Feedback skills

Managers should be from the following angles trained their feedback technology:

A few ask more about. Issue orders left and right management is difficult to achieve from the boss to "coach", "partner" role conversion. We suggest that managers and employees in the performance of communication to follow two eight principles: $80 \%$ of the time for the staff, $20 \%$ of the time for yourself, and at the $20 \%$ time, and $80 \%$ of the time in question, the $20 \%$ time for "guidance", "recommended", "issue orders left and right", because employees are often higher than the managers are more clear in their own work problems. In other words, to good questions, ask some open-ended questions to guide their own thinking and problem solving, their evaluation work in progress, but not issue orders left and right, look down from a height to tell the staff how. Two avoid using "you" 
communication. In the performance of communication course, use "we" rather than "you"; "how we solve this problem?" "What extent about this task we progress to?" In the other word, "how can I help you?" Avoid ad hominem. Try to describe the facts rather than make evaluation. When employees make some wrong or improper things, should avoid using the evaluation labels, such as "can't", "your this person how so stupid ah", but should be an objective statement of fact and his feeling for the truth.

\section{The communication throughout the performance management process}

Communication is a pervasive feature of management, similarly, performance communication throughout the whole process of performance management.

\section{1) Performance planning phase}

When planning the performance target, should take the way of interview two-way communication for many times. First of all, through the enterprise formal strategic communication channels will be the strategic planning and development of the enterprise target clearly convey to employees, the enterprise business objectives into performance indicators, produced in the same direction and goals. Second, managers will department performance target decomposition, through the communication to the goal itself, let employees clear and agree with their own work goals and performance indicators, the subordinates understand oneself should do. Then, to realize the target need to be taken by the communication methods and measures, in order to avoid employees due to the improper methods and measures, which leads to waste of resources and goals cannot achieve. In the end, is solving the problem of the resources needed to complete the objective support, do sufficient resources for smooth completion plan preparation.

\section{2) Performance in the implementation stage}

In performance in the implementation stage, the purpose of communication basically has two, one is the employee to report progress or obstacles to supervisor for help in the work, seeking help and solution; another is the supervisor of the worker work and appear to rectify the deviation between the target plans. Employees may encounter in the process of completing the planned external disorders, disabilities or other unexpected situations, these cases will affect the plan is completed. When employees to meet these conditions should be timely communication with the director, supervisor and employees are common to analyze the causes of the problem. If belong to the external obstacles, where possible, supervisor will try to help subordinates to exclude external barriers. If it is to belong to itself defective skills of employees, managers should be to provide help or guidance on skills, coaching staff to achieve the performance goals.

\section{3) The performance evaluation stage}

In this stage, managers should first appraisal methods, procedures and the application scope of the assessment results by meeting or discussions form to communicate with employees to fully, solicit opinions of the staff, make managers and employees in the performance appraisal have a agreed objective basis, reduce differences. In the process of evaluation, managers to maintain sustained and effective communication with their staff, stage performance feedback to employees.

\section{4) The performance feedback stage}

Phase feedback in the assessment of performance, specific communication content include the following aspects: One is the feedback of results. Managers will result feedback to employees on a stage performance, make employees aware of the assessment results and the target completion. The two is the check. When employees disputed, with the result of assessment can lodge a complaint, arbitration by the assessment team, to achieve the objective. Three is the performance analysis. Didn't finish the target in the work of the assessment results, the causes of joint analysis and key factors of affect the target to achieve and analyze how to eliminate the influence of these factors, according to the need for training and mentoring program and the direction of the next phase of improvement and plans. The task index over fulfils, also want to analyze the reasons, to accumulate experience for the next performance plan. Fourth, the problem about how to motivate employee occur. According to company's rewards and punishment system, according to the assessment results, combines with the employees' pay, promotion, training for a variety of rewards. Five is a plan of action. And staff to discuss and determine the next phase of work goal, complete the schedule and check the inspection plan, let employees to accomplish objectives, milestones, when feedback have a clear understanding, do PDCA closed-loop management.

\section{ACKNOWLEDGMENT}

Thanks are due to the Funding scheme for young teachers of higher school in Henan Province for providing funding on this paper.

\section{REFERENCES}

[1] Lv Xiaobai,Jin Pingping. Based on the performance of communication enterprise performance management model study [J]. Science and technology intelligence development and economy, 2006 (2).

[2] Wu Maolin. Performance communication is the key to performance management [J]. Value engineering, 2007 (3).

[3] Ding Lin YinPing. The problems existing in the theory of performance communication and its improvement measures [J]. Journal of modern business, 2006 (1).

[4] Zeng Guoping Zheng Jia. Small and medium-sized enterprise performance communication obstacle factor analysis and countermeasure research $[\mathrm{J}]$. Science and technology management research, 2007 (18).

[5] Lan Qunhui, Du Guozhi. Performance communication: the core of performance management [J]. Journal of higher education and academic research, 2007 (4).

[6] Lu Hui, Gu Qinxuan. Performance appraisal who you actually get [J]. Journal of human resources development in China, 2006 (4).

[7] Gary Dessler, Zeng Xiangquan. Human resource management [M] Renmin university of China publishing house, 2007.

[8] Qiu Qian, liu peng. Theory of performance management cycle of continued performance communication $[\mathrm{J}]$. Market modernization, 2007, (4). 